\title{
Modelagem chuva-vazão via redes neurais artificiais para simulação de vazões de uma bacia hidrográfica da Amazônia
}

\author{
Rainfall-runoff modeling via artificial neural networks for \\ simulation of streamflows from a hydrographic basin in \\ the Amazon
}

\begin{abstract}
Leonardo Melo de Mendonça $^{1}$ (D), Igor de Souza Gomide ${ }^{1}$ (D), Jaime Viana de Sousa ${ }^{1}$ (D), Claudio José Cavalcante Blanco ${ }^{2}$ (D)

1Universidade Federal Rural da Amazônia (UFRA), Capanema, PA, Brasil. E-mails: leeonardomeelo@gmail.com, igomide@gmail.com, jaime.sousa@ufra.edu.br

2Universidade Federal do Pará (UFPA), Belém, PA, Brasil. E-mail: blanco@ufpa.br
\end{abstract}

\begin{abstract}
Como citar: Mendonça, L.M., Gomide, I.S., Sousa, J.V., \& Blanco, C.J.C. (2021). Modelagem chuva-vazão via redes neurais artificiais para simulação de vazões de uma bacia hidrográfica da Amazônia. Revista de Gestão de Água da América Latina, 18 , e2.

https://doi.org/10.21168/rega.v18e2.
\end{abstract}

RESUMO: As técnicas de redes neurais artificiais (RNAs) têm sido utilizadas na previsão de variáveis hidrológicas pela capacidade de generalizar informações, o que torna a implementação de modelos menos onerosa e mais ágil. Neste estudo, foi simulado o fenômeno de conversão de chuvas em vazões de uma Sub-bacia Hidrográfica do Rio Guamá (SHRG) no Estado do Pará, Amazônia. Os modelos são baseados em RNAs de arquiteturas MLP (Multilayer Perceptron) e NARX (Nonlinear Autoregressive with Exogenous Inputs), com função de ativação Tangente Hiperbólica nos neurônios de camada oculta, sendo treinadas pelo algoritmo de treinamento supervisionado Levenberg-Marquardt. Comparando as RNAs propostas, os modelos RNA-NARX apresentaram melhores desempenhos comparados ao modelo RNA-MLP. O melhor dos modelos RNA-NARX apresentou para a fase de teste, $\mathrm{R}^{2}$ igual a 99,08\%, RMSE igual a $13,21 \mathrm{~m}^{3} \mathrm{~s}^{-1}$ e MAPE igual a 4,45\%. Esses resultados mostram a possibilidade da simulação de vazões de pequenas e médias bacias hidrográficas da Amazônia através da combinação de RNAs NARXs, principalmente de bacias com ausência ou limitação de dados.

Palavras-chave: NARX; MLP; Algoritmo Levenberg-Marquardt; Inteligência Artificial.

ABSTRACT: The techniques of artificial neural networks (ANNs) have been used in the prediction of hydrological variables due to the ability to generalize information, which makes the implementation of models less costly and more agile. In this study, the phenomenon of converting rainfall into streamflows of a Guamá River Hydrographic Sub-basin (GRHS) in the State of Pará, Amazon, was simulated. The models are based on MLP (Multilayer Perceptron) and NARX (Nonlinear Autoregressive with Exogenous Inputs) ANNs, with Hyperbolic Tangent activation function in hidden layer neurons, being trained by the supervised training algorithm Levenberg-Marquardt. Comparing the proposed ANNs, the NARX-ANN models presented better performances compared to the MLP-ANN model. The best of the NARX-ANN models presented, on average, for the training, validation and test phases, $\mathrm{R}^{2}$ equal to $99.08 \%$, RMSE equal to $13.21 \mathrm{~m}^{3} \mathrm{~s}^{-1}$ and MAPE equal to $4.45 \%$. These results show the possibility of simulating the streamflow of small and medium hydrographic basins in the Amazon through the combination of NARX-ANNs, mainly those basins with no or limited rainfall-flow data.

Keywords: NARX; MLP; Levenberg-Marquardt Algorithm; Artificial Intelligence.

Recebido: Dezembro 14, 2020. Revisado: Fevereiro 17, 2021. Aceito: Fevereiro 18, 2021. 


\section{INTRODUÇÃO}

A compreensão das características e do funcionamento dos sistemas hidrológicos é vital para a sociedade alcançar a sustentabilidade e enfrentar fenômenos naturais extremos, como enchentes e secas (Trindade \& Scheibe, 2019). Porém, a modelagem de fenômenos hidrológicos é complexa, causada principalmente pela variabilidade temporal e espacial em que as variáveis inerentes ao ciclo hidrológico podem manifestar-se em diferentes escalas (Figueiredo \& Blanco, 2017). Assim, metodologias de simulação das variáveis hidrológicas são desenvolvidas para lidar com a complexidade dos processos hidrológicos, mesmo em locais onde a disponibilidades de dados seja limitada. Para esta finalidade, existem diversas metodologias, entretanto, a que tem se sobressaído nos últimos anos são as Redes Neurais Artificiais (RNAs) (Ardabili et al., 2019). A utilização de RNAs vêm ganhando popularidade principalmente pela capacidade de generalizar informações, através da aprendizagem baseada no erro. Recentes estudos têm demonstrado as vantagens da utilização de RNAs recorrentes, como as NARXs (Nonlinear Autoregressive with Exogenous Inputs) para previsões de variáveis hidrológicas (Abou Rjeily et al., 2017; Fahimi et al., 2017; Guzman et al., 2017; Tripura \& Roy, 2017; Wunsch et al., 2018; Banihabib et al., 2018). Banihabib et al. (2019), por exemplo, compararam modelos de previsões de vazões diárias médias, que afluem em um reservatório situado no rio Dez, oeste do Irã. A barragem do reservatório controla inundações, gera energia hidrelétrica e fornece água para fins agrícolas e domésticos. Os autores utilizaram RNAs de arquiteturas NARX e um modelo Autorregressivo Integrado de Médias Móveis (ARIMA). Os resultados demostraram a superioridade do modelo NARX em todos os critérios de desempenho abordados.

A simulação do ciclo hidrológico amazônico é um grande desafio, tendo em vista a precária distribuição espacial, a baixa resolução temporal de dados observados em estações hidrometeorológicas e a complexidade da dinâmica hidrológica regional. Na parte continental, a transformação de precipitação em vazão pode apresentar não linearidades, causada por características específicas da bacia que estão inter-relacionadas como, por exemplo, as propriedades hidráulicas dos solos e de seus respectivos usos e coberturas, a incidência da chuva, a evapotranspiração e a área de contribuição (Ribeiro Neto et al., 2008). Por conta disso, a aplicabilidade de modelos hidrológicos que demandam a inserção de um grande número de parâmetros torna-se comprometida. Embora que as RNAs com arquitetura NARX tenham apresentado um grande potencial na modelagem hidrológica em vários locais do mundo, não foram evidenciados estudos com tal metodologia na região amazônica. Por outro lado, a arquitetura de RNA que é frequentemente utilizada na região para previsões de variáveis hidrológicas, é a MLP (Multilayer Perceptron) (Lima \& Guedes, 2015; Figueiredo \& Blanco, 2017; Silva et al., 2018; Salame et al., 2019; Santos Neto et al., 2020).

Os modelos chuva-vazão são muito utilizados nas avaliações de impactos ambientais de obras hidráulicas ou intervenções antrópicas em bacias hidrográficas, previsões de vazões para gerenciamento de barragens e sistemas de alertas de cheias (Almeida \& Serra, 2017). Além disso, a quantidade de estações pluviométricas é maior que a quantidade de estações fluviométricas, pois a instalação das primeiras é menos onerosa que a instalação das últimas. Essa maior disponibilidade de dados de chuva, torna os modelos chuva-vazão uma alternativa frente à falta de dados (Figueiredo \& Blanco, 2017), principalmente para pequenas e médias bacias hidrográficas, as quais são menos interessantes do ponto de vista econômico. Entretanto, essas bacias têm importância socioeconômica devido às populações do interior da Amazônia, que nelas habitam e precisam de conhecimento hidrológico para melhor gestão dos usos da água (Silva et al., 2020). Diante desta motivação, o objetivo é simular uma série temporal de vazões diárias médias de uma bacia hidrográfica média da Amazônia através de RNAs de arquiteturas MLP e NARX. Os modelos com essas arquiteturas foram avaliados, buscando o de melhor desempenho para o objetivo do estudo.

\section{MATERIAL E MÉTODOS}

\section{Área de estudo}

A sub-bacia hidrográfica do rio Guamá (SBRG) correspondente à secção transversal da estação fluviométrica Bom Jardim (Figura 1), que possui $5.001,29 \mathrm{~km}^{2}$ de área de drenagem (Figura 1). As classes de solo predominantes são o Latossolo Amarelo Distrófico e o Plintossolo Amarelo Distrófico (Figura 2a). Destaca-se, também, o uso deste solo majoritariamente na 
agropecuária (Figura 2b). A bacia têm características planas (declividade menor que 3\%) e suavemente onduladas (declividade entre 3 e 8\%) (Figura 2c), conforme a classificação da Empresa Brasileira de Pesquisa Agropecuária (1999). E, baseado na equação de Pasini (1914), estima-se que o tempo de concentração da bacia é de 38,3 horas. Logo, trata-se de uma bacia com características que favorecem a infiltração de águas pluviais através dos solos profundos e da baixa declividade (Alvarenga et al., 2012b), e com intensa alteração nas características naturais do ecossistema. 0 clima da área de estudo é o Am, conforme a classificação climática de KöppenGeiger. Isto ressalta um clima tropical, com temperaturas sempre acima dos $18^{\circ} \mathrm{C}$, altos índices de precipitação anual, e a presença de uma estação seca de pequena duração (Alvares et al., 2013), como pode ser observado nas normais climatológicas da Figura 3.

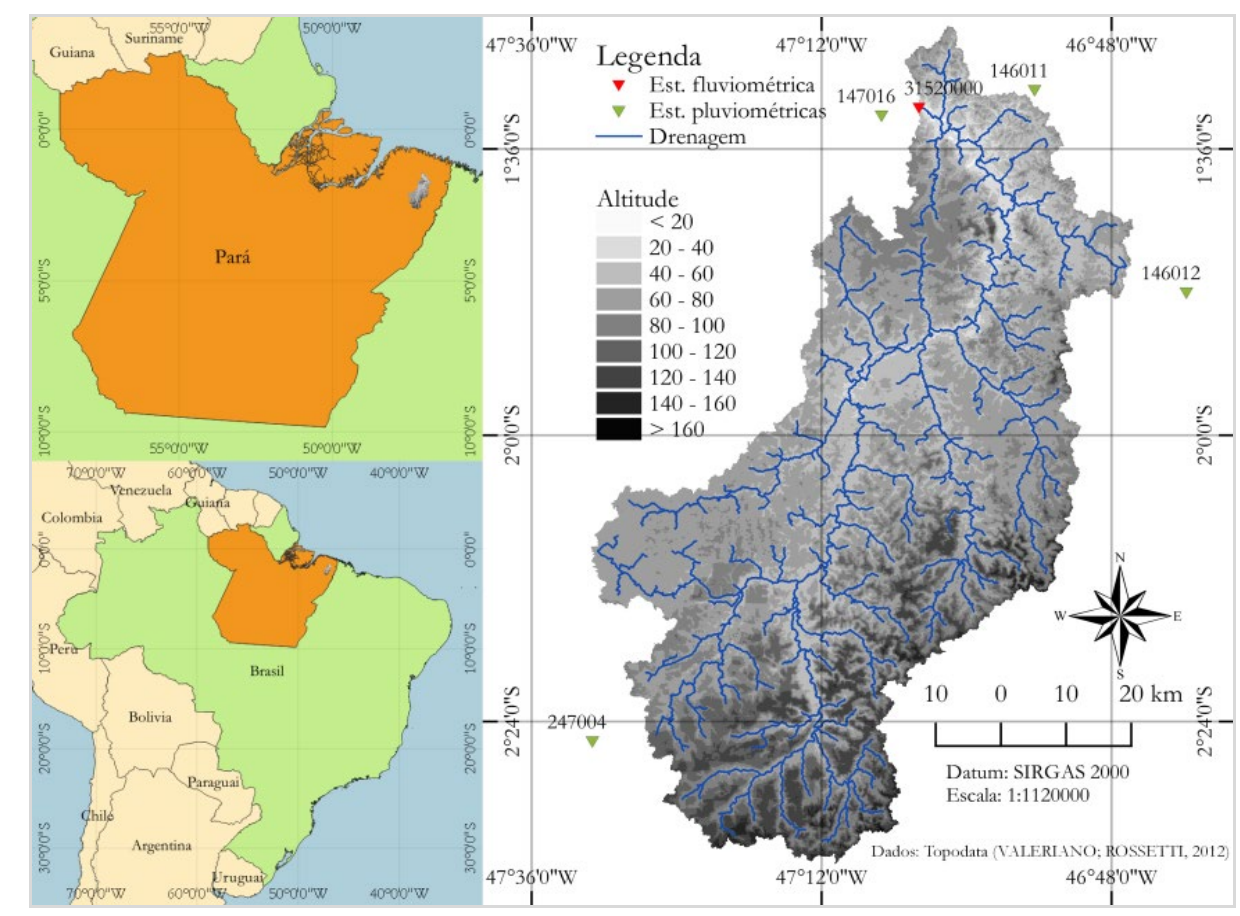

Figura 1 - Localização da sub-bacia hidrográfica do rio Guamá e das estações fluviométricas pluviométricas com dados utilizados no estudo.
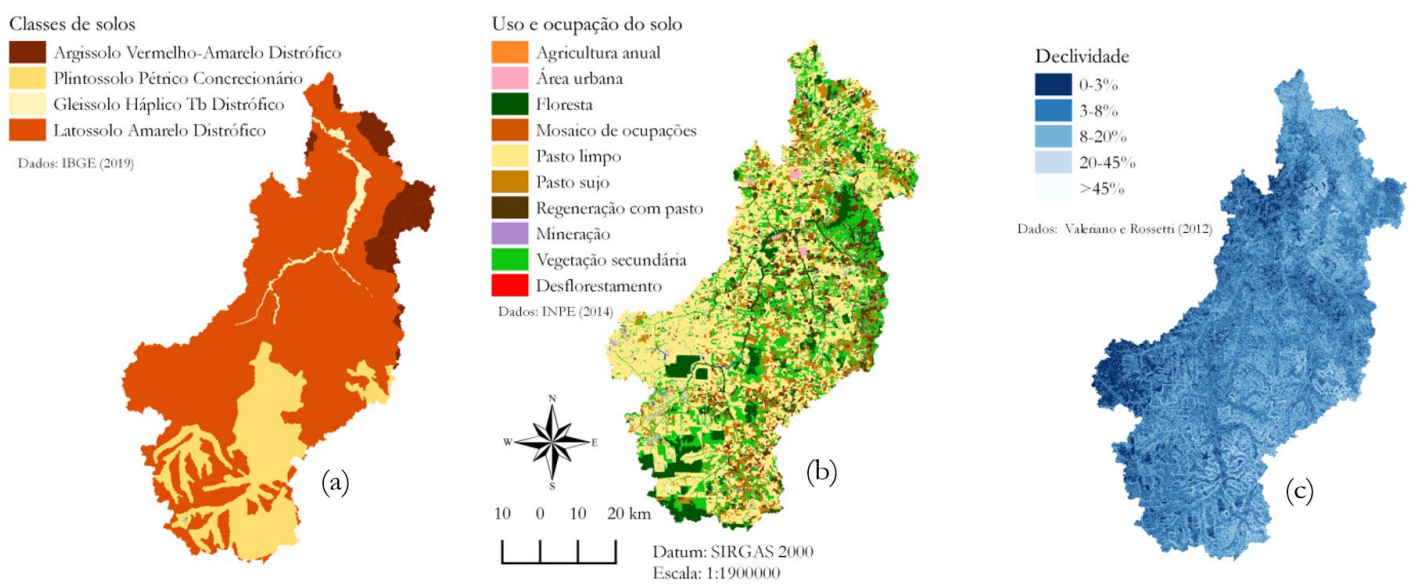

Figura 2 - Caracterização dos solos (a), uso e ocupação do solo (b) e declividade (c) da área de estudo. 


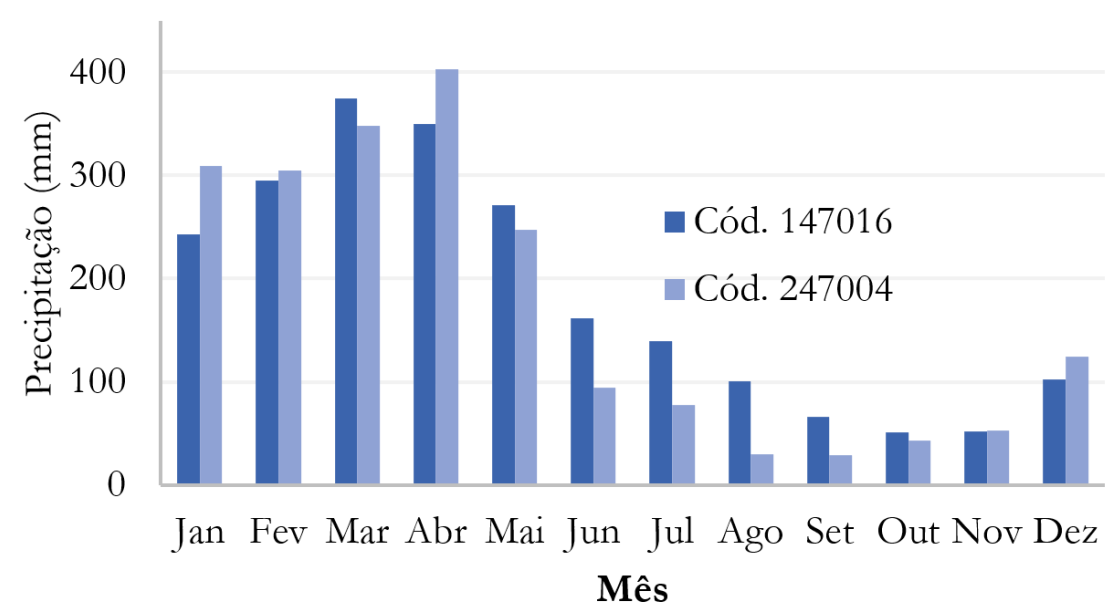

Figura 3 - Normais climatológicas observadas (1989-2018) nas estações Ourém (Código ANA: 147016) e Fazenda São Raimundo (Código ANA: 247004).

\section{Dados}

As séries de dados de vazão e chuva diárias estão disponíveis no banco de dados da Agência Nacional de Águas (2020) do Brasil. Nesse caso, foram utilizadas quatro estações pluviométricas e uma estação fluviométrica (Figura 1 e Tabela 1). 0 período de observação das chuvas e vazões vai de 01/01/2009 a 31/08/2019, totalizando 3.985 dados diários. A estatística descritiva dos dados é apresentada na Tabela 2 .

Tabela 1 - Identificação, coordenadas geográficas e tipo das estações hidrológicas com dados usadas no estudo.

\begin{tabular}{|c|c|c|c|c|c|}
\hline Código ANA & Tipo & Estação & Longitude & Latitude & Sigla \\
\hline 147016 & Pluviométrica & Ourém & $47^{\circ} 07^{\prime} 02^{\prime \prime} \mathrm{W}$ & $01^{\circ} 33^{\prime} 06^{\prime \prime S}$ & $\mathrm{P}_{1}$ \\
\hline 147011 & Pluviométrica & Santa Luzia & $46^{\circ} 54^{\prime} 22^{\prime \prime} \mathrm{W}$ & $01^{\circ} 30^{\prime} 58^{\prime \prime S}$ & $\mathrm{P}_{2}$ \\
\hline 146012 & Pluviométrica & Japim & $46^{\circ} 41^{\prime} 48^{\prime \prime} \mathrm{W}$ & $01^{\circ} 47^{\prime} 56^{\prime \prime} \mathrm{S}$ & $\mathrm{P}_{3}$ \\
\hline 247004 & Pluviométrica & Fazenda São Raimundo & $47^{\circ} 30^{\prime} 58^{\prime \prime} \mathrm{W}$ & $02^{\circ} 25^{\prime} 34^{\prime \prime} \mathrm{S}$ & $\mathrm{P}_{4}$ \\
\hline 31520000 & Fluviométrica & Bom Jardim & $47^{\circ} 03^{\prime} 56^{\prime \prime} \mathrm{W}$ & $01^{\circ} 32^{\prime} 26^{\prime \prime} \mathrm{S}$ & $\mathrm{Q}_{1}$ \\
\hline
\end{tabular}

Fonte: Agência Nacional de Águas (2020)

Tabela 2 - Estatística descritiva dos dados das estações fluviométrica e pluviométricas da ANA

\begin{tabular}{c|c|c|c|c|c}
\hline Est. descritiva & Q1 & \multicolumn{1}{c}{$\boldsymbol{P 1}$} & \multicolumn{1}{c}{$\boldsymbol{P 2}$} & \multicolumn{1}{c}{$\boldsymbol{P 3}$} \\
\hline Média & 129,38 & 6,41 & 5,66 & 6,27 & 6,55 \\
\hline Mediana & 83,41 & 1,10 & 0,70 & 0,50 & 0,00 \\
\hline Desvio padrão & 120,46 & 12,35 & 10,84 & 11,67 & 14,06 \\
\hline Min & 15,76 & 0,00 & 0,00 & 0,00 & 0,00 \\
\hline Primeiro quartil & 36,62 & 0,00 & 0,00 & 0,00 & 0,00 \\
\hline Terceiro quartil & 185,74 & 7,8 & 6,9 & 8 & 7,1 \\
\hline Máx & 644,21 & 208,00 & 125,30 & 100,50 & 131,80 \\
\hline
\end{tabular}

As falhas encontradas nas estações pluviométricas 146011 (1,59\%) e 247004 (7,68\%) foram corrigidas através do método de regressão linear (Equação 1), conforme Bertoni \& Tucci (2007). 0 método estabelece regressões lineares entre as séries temporais das estações pluviométricas com falhas (yest) e uma estação vizinha (x).

$y_{\text {est }}=a x+b$ 


\section{Redes Neurais Artificiais}

Redes Neurais Artificiais (RNAs) são técnicas de aprendizado de máquina, capazes de classificar ou modelar sistemas complexos onde há reduzida disponibilidade de dados. Os idealizadores desta ferramenta, os pesquisadores McCulloch \& Pitts (1943), inspiraram-se no funcionamento dos neurônios humanos, pela capacidade de aprendizado através da experimentação (Haykin, 2008). Os modelos fundamentados em RNAs têm a capacidade de reconhecer padrões presentes em uma série de dados, ou seja, identificam um determinado padrão de entrada e atribuem-no a um sinal de saída. Logo, obter o melhor conjunto possível de características como padrão é o primeiro passo para o sucesso de qualquer aplicação em RNAs (Silva et al., 2010). 0 neurônio artificial é a unidade básica de processamento de dados, para o qual informações $\left(\mathrm{x}_{\mathrm{n}}\right)$ são direcionadas, gerando uma resposta $\left(\mathrm{y}_{\mathrm{k}}\right)$, conforme a Equação 2. Cada Xn é ponderado por um peso sináptico $\omega_{\mathrm{kn}}$, que é somado ao parâmetro bias $b_{k}$, que modula o sinal de saída através de uma função de ativação f, ou seja, as informações fluem através de sucessivas conexões ponderadas, até gerar um sinal de resposta (Haykin, 2008).

$$
y_{k}=f\left(\sum_{n=1}^{z} w_{k n} x_{n}+b_{k}\right)
$$

A arquitetura das RNAs está alicerçada, de modo geral, na quantidade de camadas, no número de neurônios artificiais em cada camada e na tipologia de conexões entre elas. A camada de entrada é responsável por armazenar os dados, ou vetores de entrada. A camada intermediária, também conhecida como escondida ou oculta, é onde ocorre a maioria dos processamentos da rede. E, a última camada é a de saída, que recebe os valores processados e produz uma resposta (Haykin, 2008; Silva et al., 2010). Dentre as principais arquiteturas, citam-se a MLP e NARX (Figura 4), que possuem uma ampla utilização nas engenharias. A arquitetura MLP propaga os vetores de entrada para frente, camada por camada (feedfoward), ou seja, em uma única direção. Enquanto que, a arquitetura NARX retroalimenta de forma automática os intervalos defasados no tempo, gerando, assim, um modelo autorregressivo (Figura 4) (Beale et al., 2014).

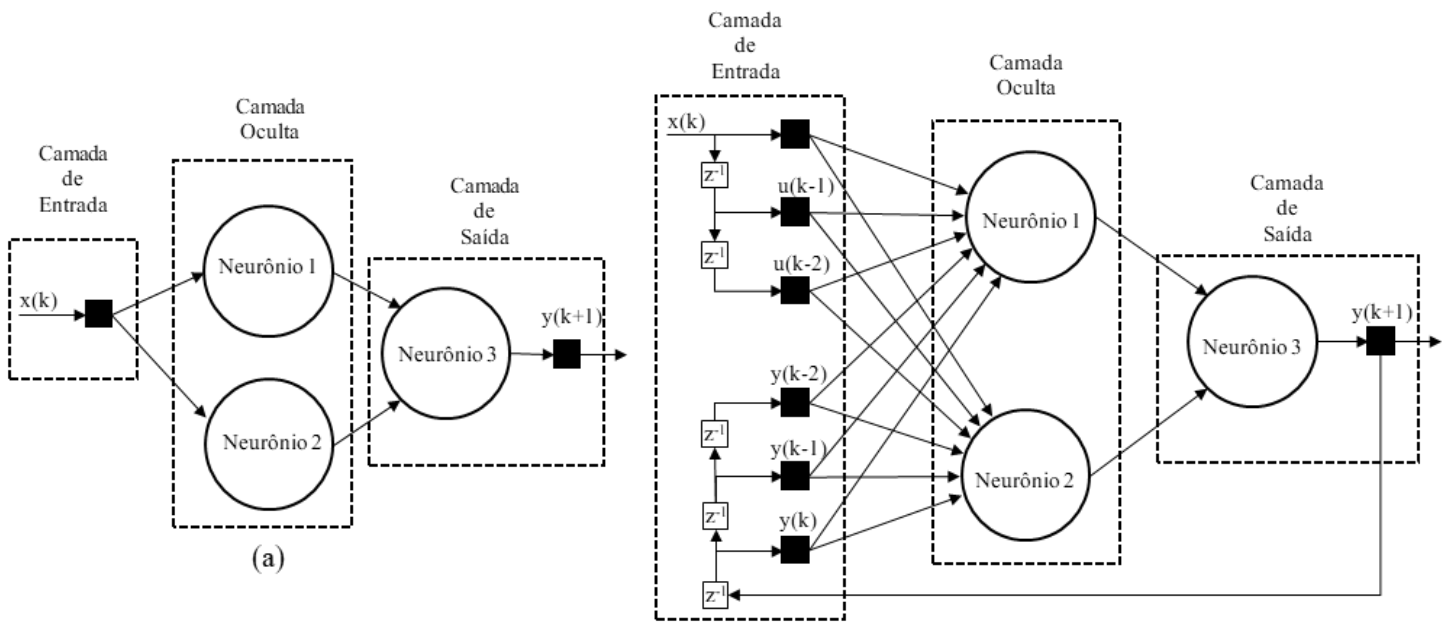

(b)

Figura 4 - Arquiteturas MLP (a) e NARX (b)

O aprendizado de uma RNA ocorre por meio de um processo iterativo aplicado aos pesos sinápticos $\left(\mathrm{w}_{\mathrm{kn}}\right)$ e bias $\left(\mathrm{b}_{\mathrm{k}}\right)$, chamado de treinamento. Conforme Haykin (2008), o treinamento de uma RNA é realizado por um algoritmo, que ajusta uma matriz de pesos sinápticos. Assim, o vetor de saída deve coincidir com um valor alvo desejado, para cada vetor de entrada. Este processo é cíclico para o conjunto amostral de treinamento até que se alcance um critério de parada, estipulado previamente. Após o treinamento, espera-se que a RNA seja capaz de generalizar informações, em outras palavras, obter saídas coerentes em vetores de entrada não utilizados no conjunto de treinamento. Espera-se que o erro mínimo encontrado no treinamento seja semelhante ao erro na simulação em um conjunto totalmente diferente. Portanto, o auxílio de um conjunto de controle é fundamental para validação cruzada do modelo, evitando fenômenos como o overffiting e o underffitng (Haykin, 2008). 
Neste estudo, os modelos chuva-vazão foram fundamentados no treinamento supervisionado de RNAs, com arquiteturas MLP e NARX, através do algoritmo de retroprogramação do erro LevenbergMarquardt. Os vetores de entrada das RNAs foram escolhidos através das análises de correlação linear, correlação cruzada, autocorrelação e autocorrelação parcial (Sudheer et al., 2002; BouFakhreddine et al., 2018). A correlação linear, ou de Pearson (Equação 3), é definida como um índice estatístico utilizado para medir o grau de relação linear entre as variáveis chuva e vazão.

$r_{x y}=\frac{1}{(n-1)} \sum_{i=1}^{n}\left(\frac{y-\bar{y}}{S_{y}}\right)\left(\frac{x-\bar{x}}{S_{x}}\right)$

Em que $r_{(x, y)}$ é o coeficiente de correlação de Pearson; y e x são as variáveis correlacionadas; $\bar{y}$ e $\bar{x}$ são as médias amostrais; $S_{x}$ e $S_{y}$ são os desvios padrões amostrais; e n é o número de observações.

A correlação cruzada (Equação 4) é o grau de intensidade entre duas séries temporais distintas em função dos intervalos defasados no tempo de uma delas. A função de correlação cruzada da amostra é útil para identificar defasagens da variável que podem ser preditores úteis da série principal. Em vista disso, buscou-se avaliar a influência entre as precipitações defasadas nas estações pluviométricas e as vazões, conforme o trabalho de Debastiani et al. (2016).

$\rho_{x y}=\frac{\operatorname{cov}\left(x_{t}, y_{t+k}\right)}{\sqrt{\operatorname{var}\left(x_{t}\right) \operatorname{var}\left(y_{t+k}\right)}}$

Em que $\rho_{x y}$ é o coeficiente de correlação cruzada; cov é a covariância amostral; var é a variância amostral e ké intervalo defasado.

O coeficiente de autocorrelação $\left(\rho_{k}\right)$, definido na Equação 5, é a correlação entre os valores da série temporal em um determinado período de tempo e os valores da mesma série em um outro momento no tempo, ou seja, entre a série e ela mesma defasada k intervalos (Figueiredo \& Blanco, 2014). Porém, há a necessidade de filtrar a influência de correlações levadas em consideração, em defasagens mais curtas da série temporal. E, com a finalidade de identificar as correlações filtradas entre as vazões e seus respectivos valores defasados, é utilizado o coeficiente de autocorrelação parcial $\left(\phi_{k k}\right)$, definido pela Equação 6 (Figueiredo \& Blanco, 2014).

$$
\begin{aligned}
\rho_{k} & =\left[\sum_{t=k+1}^{n}\left(y_{t}-\bar{y}\right)\left(y_{t-k}-\bar{y}\right)\right]\left[\sum_{t=1}^{n}\left(y_{t}-\bar{y}\right)^{2}\right]^{-1} \\
\phi_{k k} & =\left[\rho_{k}-\sum_{j=1}^{k-1}\left(\phi_{k-1 j}-\rho_{k-j}\right)\right]\left[1-\sum_{j=1}^{k-1}\left(\phi_{k-1 j} \rho_{k}\right)\right]^{-1}
\end{aligned}
$$

As séries históricas de precipitações e vazões diárias médias foram divididas em três conjuntos distintos: treinamento, validação e teste. 0 conjunto de treinamento é destinado à calibração dos parâmetros das RNAs e análises de correlações. 0 conjunto de validação é utilizado para auxiliar o treinamento supervisionado de forma iterativa, de modo a evidenciar o comportamento do erro das RNAs com dados não encontrados no treinamento. E, por fim, o de teste é destinado à avaliação estatística do desempenho dos modelos calibrados. Neste estudo, os anos hidrológicos entre 2009 a 2015 foram destinados à calibração do modelo (2.556 dados diários), os anos de 2016 e 2017 foram destinados à validação cruzada do modelo (731 dados diários), e os anos de 2018 e 2019 foram utilizadas para testar o modelo (608 dados diários). A Figura 5 mostra a divisão entre os conjuntos de dados sob a forma de um hidrograma de vazões diárias e mostra, também, as precipitações da estação pluviométrica cód. ANA: 147016 (Figura 1 e Tabela 1 e 2). 


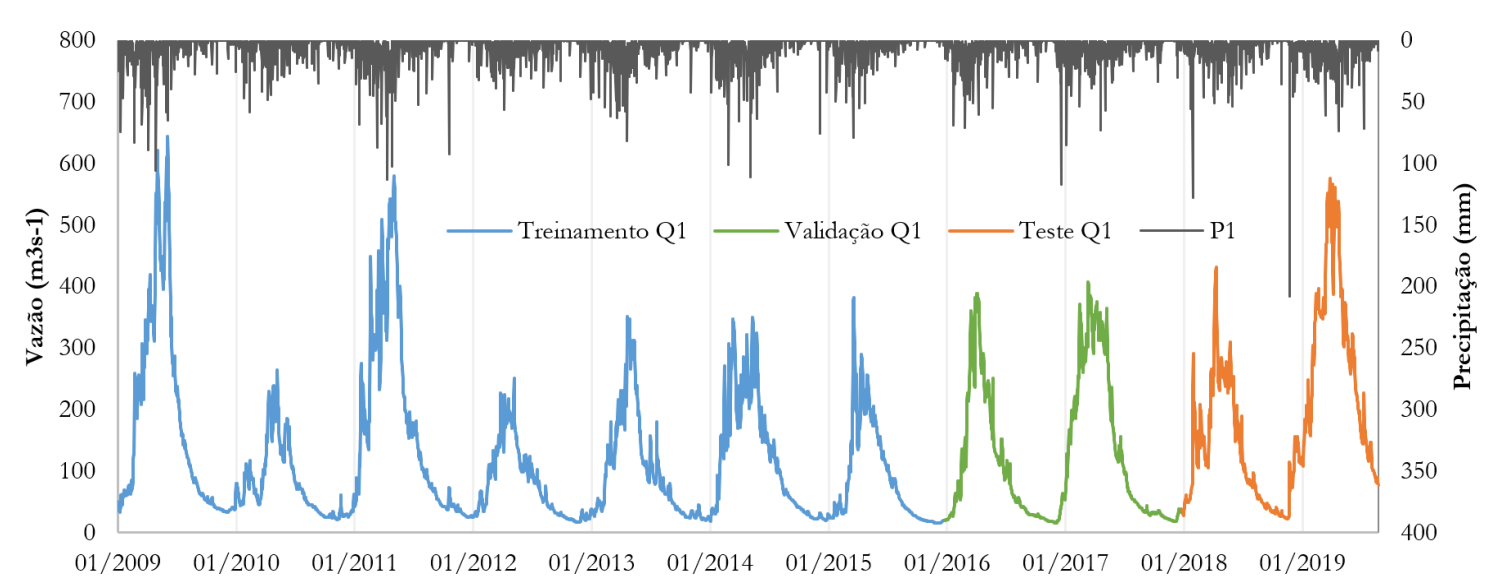

Figura 5 - Divisão dos conjuntos de treinamento, validação e teste sob a forma de hidrograma de vazões diárias

A normalização dos dados é um fator importante na calibração das RNAs. Isto atribui relevâncias igualitárias entre as diferentes magnitudes encontradas nos dados, fazendo com que o treinamento atribua importância equiparável às variáveis de entrada e à variável de saída (Maier \& Dandy, 2000). Com base nisso, os dados de precipitações e vazões foram redimensionados (Equação 7) entre -1 e 1 (Flores \& Ferreira, 2018).

$x_{n}=F_{\text {min }}+\frac{\left(x-x_{\min }\right)}{\left(x_{\max }-x_{\min }\right)}\left(F_{\max }-F_{\text {min }}\right)$

Em que $\mathrm{x}_{\mathrm{n}}$ e x são as variáveis normalizada e observada, respectivamente; $\mathrm{x}_{\text {mín }}$ e $\mathrm{x}_{\text {máx }}$ são os valores amostrais mínimo e máximo; e, Fmín e Fmáx são os intervalos mínimo e máximo desejados.

As RNAs foram construídas através da biblioteca Neural Networks Toolbox do software Matlab 2014b. Assim como aplicado por Santos Neto et al. (2020), o número ideal de neurônios nas camadas ocultas foi determinado através do método das iterações sucessivas, implementando-se de 1 a 30 neurônios artificiais, visando encontrar qual configuração proporciona menor erro de simulação. Além disso, a função de ativação tangente hiperbólica sigmoidal (tansig) foi utilizada nas camadas escondidas. Essa função estabelece a resposta em um intervalo conhecido entre -1 e 1 . Na camada de saída foi utilizada a função linear pura (purelin).

0 treinamento supervisionado das RNAs foi feito com o algoritmo de retroprogramação Levenberg-Marquardt, um dos mais usados para previsões de séries temporais, e vastamente utilizado na previsão de variáveis hidrológicas (Oyebode \& Stretch, 2019). Este algoritmo é uma adaptação do método Gauss-Newton, abordando um treinamento de segunda ordem com a aproximação de uma matriz Hessiana (Sahoo \& Jha, 2013). A partir disso, o ajuste dos parâmetros dos pesos sinápticos ( $W_{k}$ ) e bias ( $b_{k}$ ) foi elaborado (Equação 8).

$w_{(k+1)}=w_{k}-\left(J_{k}^{T} J_{k}+\mu I\right)^{-1} J_{k} e_{k}$

Onde $w_{\mathrm{k}}$ é o peso sináptico, $\mathrm{J}_{\mathrm{k}}^{\mathrm{T}} \mathrm{J}_{\mathrm{k}}$ representa uma matriz Hessiana aproximada, $\mathrm{e}_{\mathrm{k}}$ é o erro quadrático associado a cada iteração, Jk é uma matriz Jacobiana, I é uma matriz identidade e $\mu$ é uma constante de aprendizado.

No decorrer de todo o processo de treinamento, o desempenho de aprendizado da RNA foi monitorado por validação cruzada, utilizando-se o conjunto de validação, a fim de identificar o momento em que não houvesse mais ganho de desempenho, identificando o momento ideal de interrupção das iterações.

\section{Critérios de desempenho}

Para a análise de desempenho do modelo, foram considerados os seguintes critérios. Coeficiente de determinação $\left(\mathrm{R}^{2}\right)$, que é o quadrado da Equação 3, considerando as vazões observadas e estimadas pelo modelo. Nesse caso, quanto mais próximo de 1, maior o ajuste de previsão. Raiz do Erro Quadrático Médio (RMSE), dado pela Equação 9, o qual sendo igual a zero indica uma estimativa 
perfeita do modelo. E o Erro absoluto percentual médio (MAPE), dado pela Equação 10, sendo determinado entre as vazões observadas e estimadas.

$R M S E=\sqrt{\frac{\sum_{l}^{n}\left(Q_{e}-Q\right)^{2}}{n}}$

MAPE $=\frac{\sum_{l}^{n}\left(\frac{\left|Q_{e}-Q\right|}{Q}\right)}{n} 100$

Nas Equações 9 e 10, Q $\left(\mathrm{m}^{3} \mathrm{~s}^{-1}\right)$ é a vazão observada, $\mathrm{Q}_{\mathrm{e}}\left(\mathrm{m}^{3} \mathrm{~s}^{-1}\right)$ é a vazão estimada, e $\mathrm{n}$ é o número de observações .

Também foi utilizada a Contribuição Relativa (CR) (Garson, 1991), para avaliar a influência de cada variável contida na camada de entrada das RNAs. 0 método avalia os pesos sinápticos provenientes de cada variável e atribui um percentual de relevância à estimativa dos valores de saída (Equação 11).

$$
C R=\frac{\sum_{l}^{n_{o}}\left(w_{j o} \frac{w_{i j}}{\sum_{l}^{n_{i}} w_{i j}}\right)}{\sum_{l}^{n_{i}}\left[\sum_{l}^{n_{o}}\left(w_{j o} \frac{w_{i j}}{\sum_{l}^{n_{i}} w_{i j}}\right)\right]}
$$

Em que $w_{\text {ij }}$ é o peso atribuído ao vetor de entrada i em direção ao neurônio oculto j, wjo é o peso atribuído à resposta do neurônio j em direção ao neurônio de saída o, $\mathrm{n}_{\mathrm{o}}$ é o número de neurônios ocultos e $\mathrm{n}_{\mathrm{i}}$ é o número de variáveis de entrada.

\section{RESULTADOS E DISCUSSÃo}

A Tabela 3 mostra as correlações lineares entre as variáveis do conjunto de treinamento. É possível observar que as correlações entre as estações pluviométricas foram positivas e consideradas entre pouco a moderadamente significativas $(0,21$ a 0,45$)$. Este resultado evidencia o alto índice de variabilidade espacial das chuvas diárias na área de estudo, o que influencia diretamente no comportamento diário da vazão em $\mathrm{Q}_{1}$, tendo em vista que a principal entrada de água no sistema é a precipitação. As correlações positivas e pouco significativas entre as precipitações e a vazão $Q_{1}(0,31$ a 0,39 ) sugerem que as vazões observadas na SHRG estão sofrendo influência de outras variáveis. Este resultado era esperado pois as vazões não dependem somente das chuvas, segundo as concepções do balanço hidrológico. Características como as taxas de evapotranspiração podem apresentar uma considerável representatividade na variabilidade de $\mathrm{Q}_{1}$, haja vista a manutenção dos altos percentuais de umidade relativa do ar da região amazônica, principalmente em períodos secos (Rocha et al., 2017). Além disso, os tipos e usos de solo associados à baixa declividade, predominante na SHRG, favorecem os escoamentos subsuperficiais e subterrâneos na SHRG. Segundo Alvarenga et al. (2011a), a dinâmica hidráulica nas camadas subsuperficiais e subterrâneas são mais lentas e sutis que as observadas através do escoamento superficial, o que pode dificultar a identificação imediata na escala diária através das correlações lineares.

Tabela 3 - Matriz de correlações lineares do conjunto de treinamento

\begin{tabular}{|c|c|c|c|c|c|}
\hline Variável & $\mathbf{Q}_{1}$ & $\mathbf{P}_{1}$ & $\mathbf{P}_{2}$ & $\mathbf{P}_{3}$ & $\mathbf{P}_{4}$ \\
\hline $\mathrm{Q}_{1}$ & 1 & 0,32 & 0,33 & 0,31 & 0,39 \\
\hline $\mathrm{P}_{1}$ & 0,32 & 1 & 0,45 & 0,39 & 0,22 \\
\hline $\mathrm{P}_{2}$ & 0,33 & 0,45 & 1 & 0,31 & 0,24 \\
\hline $\mathrm{P}_{3}$ & 0,31 & 0,39 & 0,31 & 1 & 0,21 \\
\hline $\mathrm{P}_{4}$ & 0,39 & 0,22 & 0,24 & 0,21 & 1 \\
\hline
\end{tabular}

Os coeficientes de correlação cruzada e autocorrelação parcial são mostrados na Figura 6. Os coeficientes de correlação cruzada mostram relações positivas e pouco significantes entre a vazão $Q_{1}$ 
e as precipitações $\mathrm{P}_{1}, \mathrm{P}_{2}$ e $\mathrm{P}_{3}$ (Figuras 6a-c), no intervalo de 1 a 10 dias defasados, com intervalo de confiança de 99\%. Além disso, as correlações entre a vazão $\mathrm{Q}_{1}$ e $\mathrm{P}_{4}$ (Figura 6d) são positivas e moderadamente significativas, superiores às demais estações, com o mesmo intervalo de análise e de confiança. Entretanto, é evidente o decrescimento gradual dos coeficientes em função das defasagens. Esta curva de decrescimento condiz com a estimativa do tempo de concentração (38,5 horas), pois não há aumento de correlação em função dos dias defasados. Por outro lado, a função de autocorrelação parcial (Figura 6e) confirma a associação entre as vazões $\mathrm{Q}_{1}$ e seus intervalos defasados. Com intervalo de confiança de 99\%, os dias 1, 3 e 10 mostraram correlação positivas e significativas entre as variáveis, enquanto que o dia 2 defasado apresentou correlação negativa e significante. Com base nisso, fica evidente que a covariação entre $Q_{(t)}$ e $Q_{(t-1)}$ é significativa, mostrando indícios de que a recarga do rio tem grande subsistência a partir do escoamento subterrâneo, o que faz jus às características da SHRG, pois Latossolos associados às baixas declividades, como observado na SHRG, são responsáveis por diminuir ou até mesmo cessar a resposta de escoamento superficial, logo a fração que não é devolvida à atmosfera por evapotranspiração infiltra no solo até camadas mais profundas, indo recarregar o aquífero (Allasia et al., 2004).
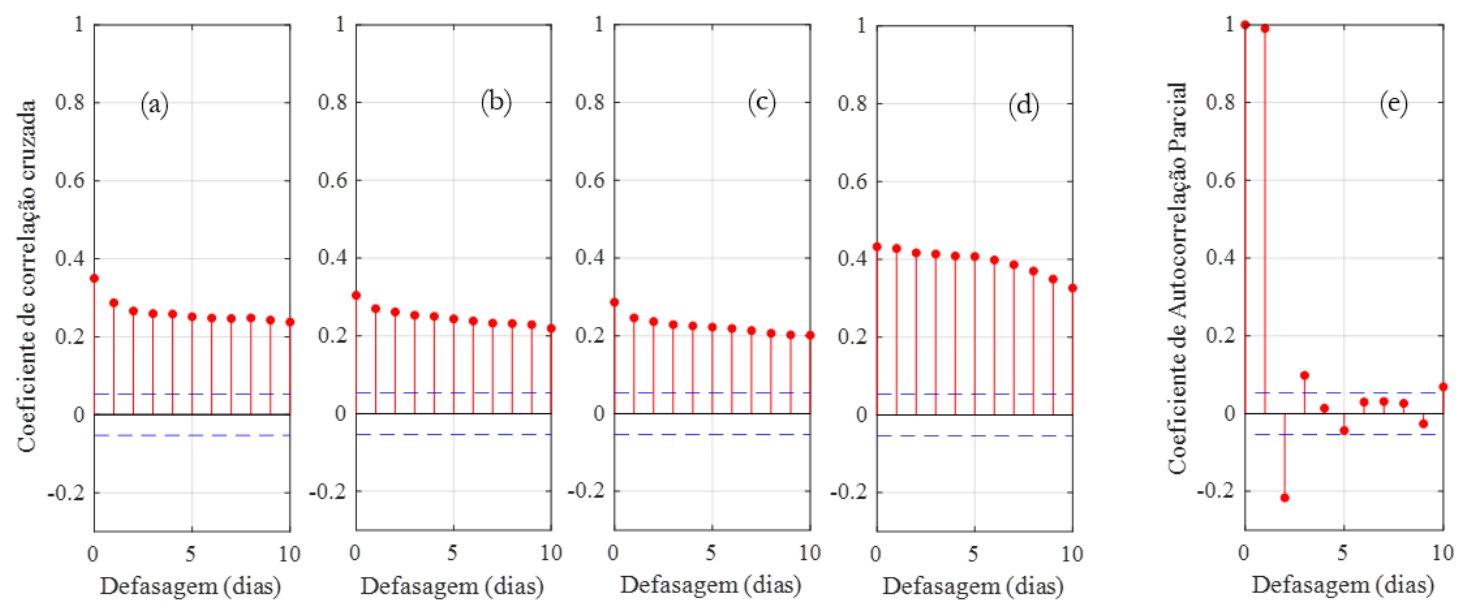

Figura 6 - Coeficientes de correlação cruzada entre vazão Q e precipitação em $P_{1}$ (a), precipitação em $P_{2}$ (b), precipitação em $\mathrm{P}_{3}$ (c) e precipitação em $\mathrm{P}_{4}$ (d). Coeficientes de autocorrelação parcial de vazões $\mathrm{Q}_{1}(\mathrm{e})$, com intervalo de intervalo de confiança de 99\% (linha tracejada).

A partir dos resultados encontrados nas análises de correlações foram propostas as seguintes arquiteturas de RNAs (Tabela 4): uma RNA-MLP de referência, com quatro vetores de entrada, representando cada estação pluviométrica, para simular as vazões da estação fluviométrica analisada. Ainda, foram elaborados dois modelos baseados em RNAs-NARX, para avaliar o potencial de simulação a partir das defasagens das variáveis, sendo inseridas de forma automática. 0 modelo RNA-NARX01 possui os mesmos vetores descritos na RNA-MLP, e retroalimentações das vazões defasadas 1, 2, 3 e 10 dias no tempo, que são reinseridas pelo próprio algoritmo de simulação. Por fim, o modelo RNANARX02, possuindo, além das características do modelo RNA-NARX01, teve a implementação automatizada de precipitações defasadas no intervalo de 1 a 10 dias.

Tabela 4 - Arquiteturas de RNAs propostas

\begin{tabular}{|c|c|c|c|c|}
\hline Modelo & Vetores de entrada & Atrasos de entrada & Retroalimentação & Saída \\
\hline RNA-MLP & 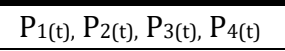 & - & - & $\mathrm{Q}_{\mathrm{t}}$ \\
\hline RNA-NARX01 & $P_{1(t)}, P_{2(t)}, P_{3(t)}, P_{4(t)}$ & - & $Q_{(t-1)}, Q_{(t-2)}, Q_{(t-3)}, Q_{(t-10)}$ & $\mathrm{Q}_{\mathrm{t}}$ \\
\hline \multirow{3}{*}{ RNA-NARX02 } & \multirow{3}{*}{$P_{1(t)}, P_{2(t)}, P_{3(t)}, P_{4(t)}$} & $P_{1(t-1)}, P_{2(t-1)}, P_{3(t-1)}, P_{4(t-1)}$ & \multirow{3}{*}{$Q_{(t-1)}, Q_{(t-2)}, Q_{(t-3)}, Q_{(t-10)}$} & \multirow{3}{*}{$Q_{t}$} \\
\hline & & $P_{1(t-2)}, P_{2(t-2)}, P_{3(t-2)}, P_{4(t-2)}, \ldots$ & & \\
\hline & & $\mathrm{P}_{1(\mathrm{t}-10),} \mathrm{P}_{2(\mathrm{t}-10)}, \mathrm{P}_{3(\mathrm{t}-10)}, \mathrm{P}_{4(\mathrm{t}-10)}$ & & \\
\hline
\end{tabular}

A Tabela 5 mostra os resultados das RNAs propostas para simulação das vazões diárias na SBRG. Nota-se que em todos os modelos, os resultados dos critérios de desempenho nos processos de treinamento, validação e teste foram próximos, ou seja, é evidente que as RNAs generalizaram os 
padrões identificados no treinamento e que ainda estavam presentes nos conjuntos de validação e teste. Em todos os modelos otimizados, dois neurônios na camada oculta foram ideais para as simulações. Características com baixa variabilidade temporal no período estudado, como por exemplo, a área de contribuição e as características geológicas e geomorfológicas da SHRG podem ter sido aprendidas, com o ajuste dos pesos sinápticos e bias. Entretanto, o modelo RNA-MLP obteve um resultado bem inferior aos demais. 0 coeficiente $\mathrm{R}^{2}$ alcançou 28,78\%, erros RMSE de 13,21 $\mathrm{m}^{3} \mathrm{~s}^{-1} \mathrm{e}$ MAPE de 120,86\%. Este resultado diretamente ligado à ausência das defasagens temporais, corroborando com as contribuições determinísticas explicitadas nas análises de correlações. Os modelos RNA-NARX01 e RNA-NARX02 apresentaram excelentes resultados, e muito próximos entre si. Entretanto, o primeiro alcançou estes resultados com menos dados de entrada, mesmo não havendo diferenças significativas entre as duas séries temporais simuladas pelos modelos (Teste-F com p-valor $=0,9514$ ). 0 coeficiente $\mathrm{R}^{2}$ do modelo RNA-NARX01 foi de 99,08\%, demonstrando excelentes ajustes dos dados simulados em relação aos dados observados no conjunto de teste. O RMSE de 13,21 $\mathrm{m}^{3} \mathrm{~s}^{-1} \mathrm{e}$ MAPE de 4,63\% são considerados satisfatórios do ponto de vista hidrológico. A curva de redução do erro quadrático em função das iterações de treinamento do modelo RNA-NARX01 pode ser observada na Figura 7. 0 modelo encontrou os melhores parâmetros na iteração 230. A busca foi mantida até a iteração 330, a partir da qual o treinamento foi encerrado, pois não foram mais observadas variações importantes nos valores do RMSE, aferidas no conjunto de validação.

Tabela 5 - Valores dos critérios de desempenho dos modelos propostos

\begin{tabular}{c|c|c|c|c}
\hline \multicolumn{2}{c}{ Modelo } & $\boldsymbol{R}^{\mathbf{2}}(\%)$ & MAPE (\%) & RMSE $\left(\mathbf{m}^{3} \boldsymbol{s}^{-1}\right)$ \\
\hline RNA-MLP & Treinamento & 32,59 & 94,39 & 95,45 \\
\hline$(4-2-1)^{*}$ & Validação & 31,67 & 103,11 & 92,34 \\
\hline RNA-NARX01 & Teste & 28,78 & 78,67 & 120,86 \\
\hline$(8-2-1)^{*}$ & Treinamento & 98,77 & 5,38 & 12,88 \\
\hline & Validação & $\mathbf{9 9 , 1 7}$ & $\mathbf{4 , 6 3}$ & $\mathbf{1 0 , 1 5}$ \\
\hline RNA-NARX02 & Teste & $\mathbf{9 9 , 0 8}$ & $\mathbf{4 , 4 5}$ & $\mathbf{1 3 , 2 1}$ \\
\hline$(48-2-1)^{*}$ & Treinamento & 98,80 & 6,93 & 12,75 \\
\hline & Validação & 99,09 & 6,31 & 10,65 \\
\hline
\end{tabular}

$*\left(n^{\circ}\right.$ de entradas $-n^{\circ}$ de neurônios ocultos $-n^{\circ}$ de neurônios de saída $)$

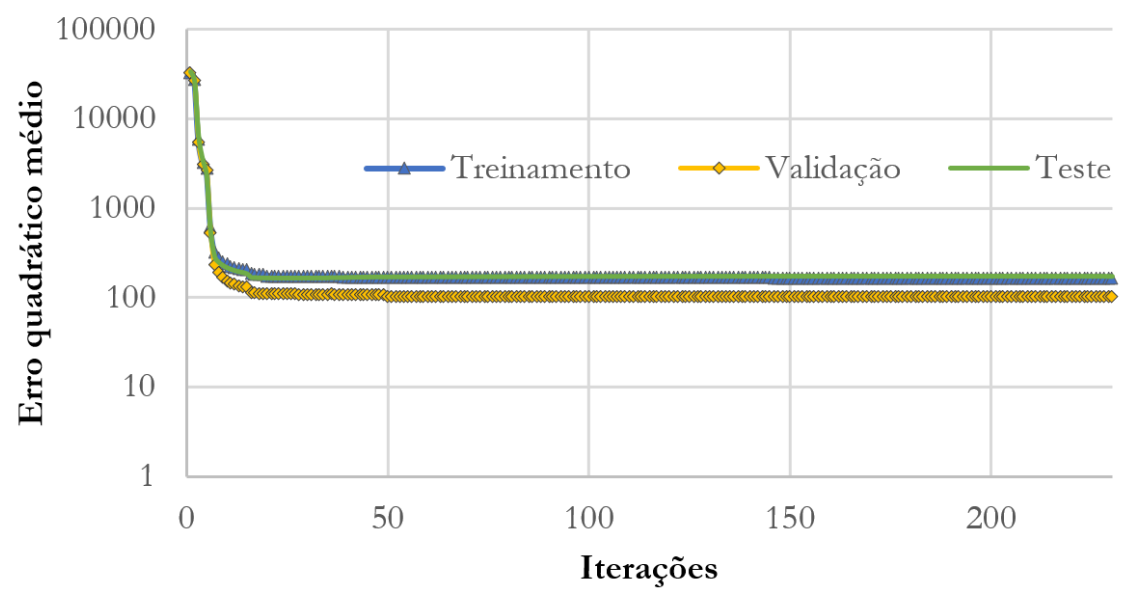

Figura 7 - Curvas de redução do erro quadrático médio em função das iterações de treinamento de RNANARX01

Os gráficos de dispersão (Figura 8) apresentam a relação entre as vazões observadas e simuladas pelo modelo RNA-NARX01, nas fases de treinamento, validação e teste. As vazões mínimas 
apresentaram melhores resultados em relação às vazões máximas, no conjunto de teste. A vazão mínima observada no dia 21/11/2018, de 22,66 $\mathrm{m}^{3} \mathrm{~s}^{-1}$, foi simulada como 23,37 $\mathrm{m}^{3} \mathrm{~s}^{-1}$, ou seja, com erro absoluto percentual de 3,15\%. O maior erro encontrado em vazões mínimas foi no dia $06 / 11 / 2018$ com $27,23 \%$ de erro percentual, sendo as vazões observada e simulada nos valores de $29,17 \mathrm{~m}^{3} \mathrm{~s}^{-1}$ e $37,11 \mathrm{~m}^{3} \mathrm{~s}^{-1}$, respectivamente. Enquanto isso, a vazão máxima observada no dia $11 / 01 / 2019$, de $566,52 \mathrm{~m}^{3} \mathrm{~s}^{-1}$, foi simulada como $490,58 \mathrm{~m}^{3} \mathrm{~s}^{-1}$, obtendo erro absoluto percentual de 13,40\%. 0 maior erro encontrado para as vazões máximas foi no dia 13/04/2019 com 20,27\% de erro percentual, sendo as vazões observada e simulada nos valores de 424,08 $\mathrm{m}^{3} \mathrm{~s}^{-1}$ e $510,02 \mathrm{~m}^{3} \mathrm{~s}^{-1}$, respectivamente. Para a visualização de toda a série temporal observada e simulada pelo modelo RNANARX01, os hidrogramas de vazões nas etapas de treinamento, validação e teste são mostrados na Figura 9.

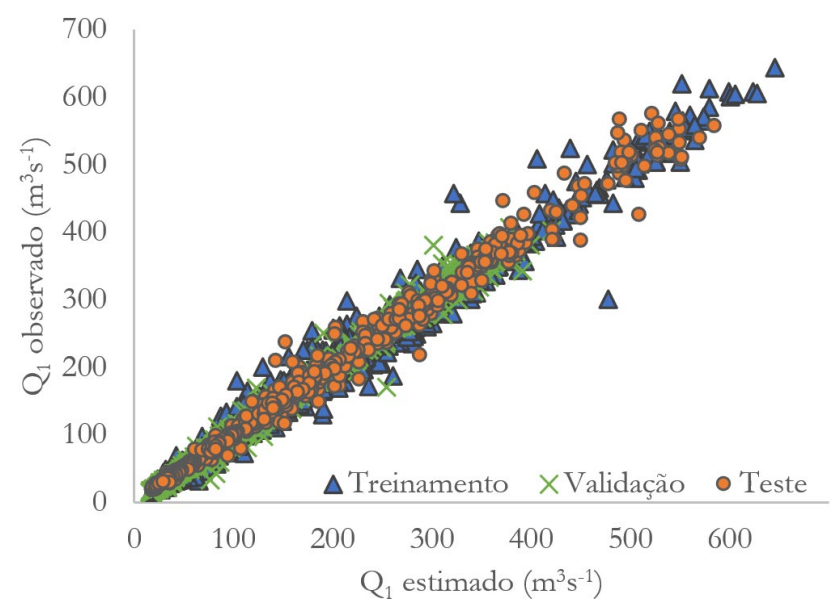

Figura 8 - Gráficos de dispersão de treinamento (a), validação (b) e teste (c) do modelo RNA-NARX01.

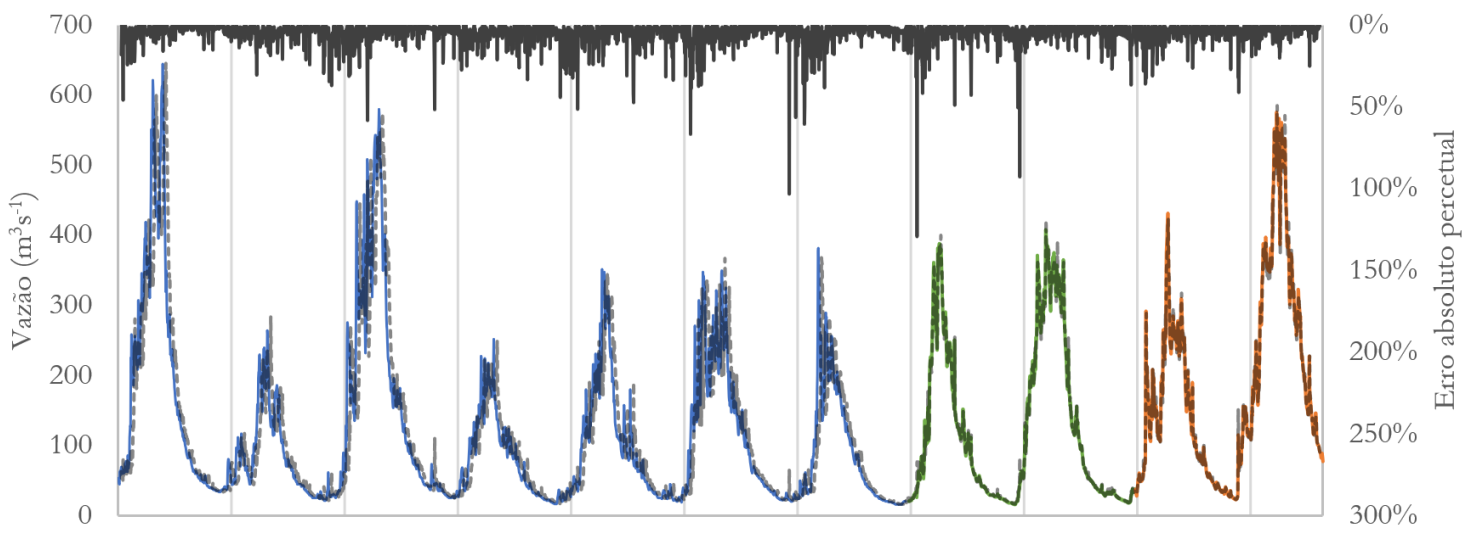

01/2009 01/2010 01/2011 01/2012 01/2013 01/2014 01/2015 01/2016 01/2017 01/2018 01/2019

Treinamento

- Validação

Teste

- Simulações

Erro percentual

Figura 9 - Hidrogramas de vazões observadas e simuladas pelo modelo RNA-NARX01 nas etapas de treinamento, validação e teste.

A Figura 10 mostra as contribuições relativas (CRs) dos vetores de entrada dos modelos em ordem decrescente. Analisando a $\mathrm{CR}$ dos vetores de entrada (Figura 10) relacionados às estações pluviométricas, observa-se que o vetor $\mathrm{P}_{1}$ (Estação Ourém) foi o que apresentou maior percentual nos modelos, enquanto que a de menor influência foi o vetor $\mathrm{P}_{4}$ (Estação Fazenda São Raimundo). Desta forma, subentende-se que a distância entre a estação hidrometeorológica e a estação fluviométrica é proporcional à CR nas RNAs, o que condiz com ideia da necessidade de um maior tempo que a precipitação precisaria para influenciar na estação $Q_{1}$. No entanto, a implementação de defasagens das precipitações faz com que os CRs da precipitação sejam redistribuídos entre si. 
As defasagens em $\mathrm{Q}_{1}$ foram as mais decisivas às simulações dos modelos. 0 vetor de entrada $\mathrm{Q}_{1(\mathrm{t} \text { - }}$ 1) obteve CR nos modelos RNA-NARX01 e RNA-NARX02 de 29,06 e 55,60\%, respectivamente. Esta discrepância dar-se pela implementação das defasagens de precipitação, que diminuíram o CR de Q1(t2) e $Q_{(t-3)}$, e aumentam em $Q_{1(t-1)}$. Pois, é possível que as precipitações defasadas estejam disputando pela generalização dos mesmos fenômenos, visto que podem estar associadas diretamente à recarga gradual do aquífero.
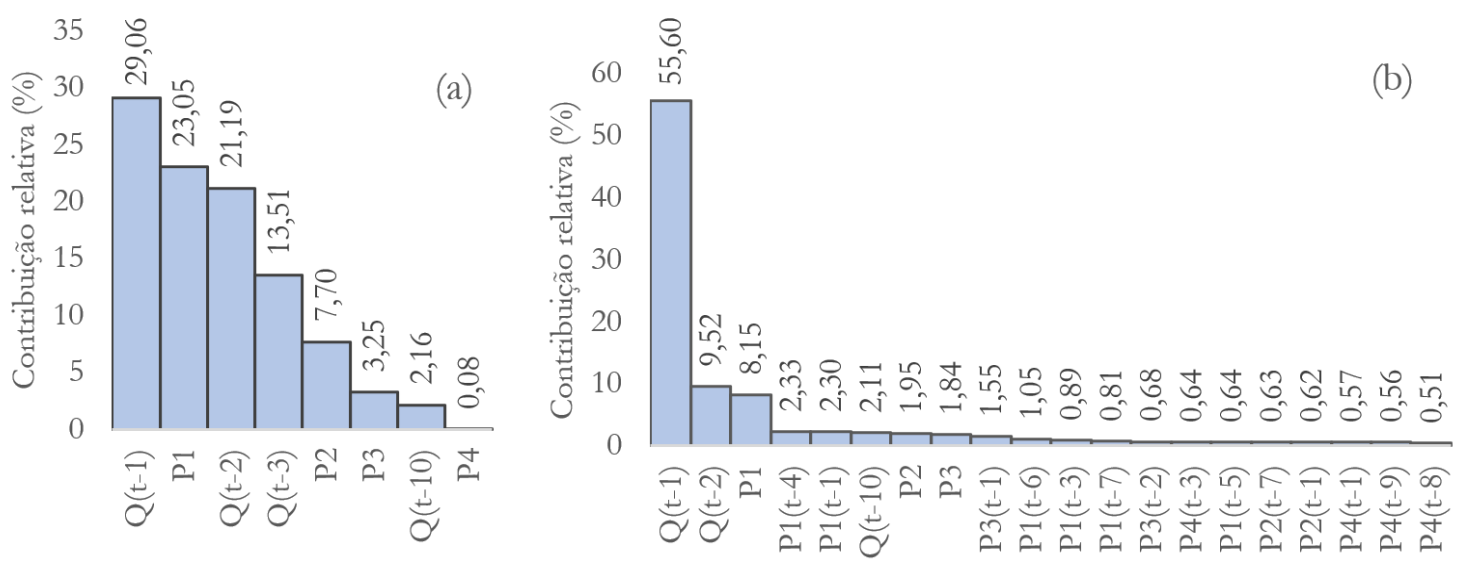

Figura 10 - Contribuições relativas dos vetores de entrada nos modelos (a) RNA-NARX01 e (b) RNA-NARX02

\section{CONCLUSÕES}

Esta pesquisa permitiu elaborar modelos hidrológicos chuva-vazão com dados de uma Sub-bacia Hidrográfica do Rio Guamá, no Estado do Pará, Amazônia. A seleção dos vetores de entrada através de coeficientes de correlações linear, cruzada, autocorrelação e autocorrelação parcial mostrou-se ser uma alternativa interessante, possibilitando identificar quais estações pluviométricas e defasagens nas séries temporais são relevantes à simulação das vazões. Foi constatado que em todos os modelos autorregressivos, os resultados dos processos de treinamento, validação e teste foram próximos, mostrando que as RNAs reconheceram os padrões identificados no treinamento e que ainda estavam presentes nos conjuntos de validação e teste. Entretanto, o modelo RNA-NARX01 mostrou-se mais adequado para a simulação das vazões diárias da área de estudo, principalmente pela menor necessidade de dados de entrada. Nesse caso, foram utilizados oito vetores de entrada, dois neurônios artificiais na camada oculta e um neurônio na camada de saída. As análises estatísticas dos hidrogramas de vazões simulado aferiram $\mathrm{R}^{2}$ igual a 99,08\%, RMSE igual a 13,21 $\mathrm{m}^{3} \mathrm{~s}^{-1}$ e MAPE igual a 4,45\%. As análises de CRs mostraram que a característica autorregressiva é a principal variável preditora, a qual está diretamente relacionada com as características do escoamento subsuperficial e subterrâneo. Esses resultados mostram a possibilidade da simulação de vazões de pequenas e médias bacias hidrográficas da Amazônia através da combinação entre RNAs NARXs, principalmente, aquelas bacias com ausência ou limitação de dados hidrometeorológicos.

\section{REFERÊNCIAS}

Abou Rjeily, Y., Abbas, O., Sadek, M., Shahrour, I., \& Hage Chehade, F. (2017). Flood forecasting within urban drainage systems using NARX neural network. Water Science and Technology, 76(9), 2401-2412.

Agência Nacional de Águas - ANA. (2020). Séries históricas de estações. Brasília. Recuperado em 14 de dezembro de 2020, de http://www.snirh.gov.br/hidroweb/serieshistoricas

Allasia, D. G., Collischonn, W., Tucci, C. E. M., Germano, A., Collischonn, B., \& Failache, N. (2004). Modelo hidrológico da bacia do Alto Paraguai. In Anais do III Simpósio de Recursos Hídricos do Centro-Oeste (Vol. 20, CD ROM). Goiânia: SBRH.

Almeida, L., \& Serra, J. C. V. (2017). Modelos hidrológicos, tipos e aplicações mais utilizadas. Revista da FAE, 20(1), 129-137.

Alvarenga, C. C., Mello, C. R., Mello, J. M., \& Viola, M. R. (2011a). Continuidade espacial da condutividade hidráulica saturada do solo na bacia hidrográfica do Alto Rio Grande, MG. Revista Brasileira de Ciência do Solo, 35(5), 1745-1758. 
Alvarenga, C. C., Mello, C. R., Mello, J. M., Silva, A. M., \& Curi, N. (2012b). Índice de qualidade do solo associado à recarga de água subterrânea (IQS RA) na Bacia Hidrográfica do Alto Rio Grande, MG. Revista Brasileira de Ciência do Solo, 36(5), 1608-1619.

Alvares, C. A., Stape, J. L., Sentelhas, P. C., de Moraes Gonçalves, J. L., \& Sparovek, G. (2013). Köppen's climate classification map for Brazil. Meteorologische Zeitschrift, 22(6), 711-728.

Ardabili, S., Mosavi, A., Dehghani, M., \& Várkonyi-Kóczy, A. R. (2019). Deep learning and machine learning in hydrological processes climate change and earth systems a systematic review. In International Conference on Global Research and Education (pp. 52-62). Cham: Springer.

Banihabib, M. E., Ahmadian, A., \& Valipour, M. (2018). Hybrid MARMA-NARX model for flow forecasting based on the large-scale climate signals, sea-surface temperatures, and rainfall. Hydrology Research, 49(6), 17881803.

Banihabib, M. E., Bandari, R., \& Peralta, R. C. (2019). Auto-regressive neural-network models for long lead-time forecasting of daily flow. Water Resources Management, 33(1), 159-172.

Beale, M. H., Hagan, M. T., \& Demuth, H. B. (2014). Neural network toolbox: user's guide (Vol. 2, pp. 77-81). Natick, MA: MathWorks.

Bertoni, J. C., \& Tucci, C. E. M. (2007). Hidrologia: ciência e aplicação (pp. 177-241). Porto Alegre: UFRGS.

Bou-Fakhreddine, B., Mougharbel, I., Faye, A., Abou Chakra, S., \& Pollet, Y. (2018). Daily river flow prediction based on Two-Phase Constructive Fuzzy Systems Modeling: a case of hydrological-meteorological measurements asymmetry. Journal of Hydrology, 558, 255-265.

Debastiani, A. B., Silva, R. D., \& Rafaeli Neto, S. L. (2016). Eficácia da arquitetura MLP em modo closed-loop para simulação de um Sistema Hidrológico. Revista Brasileira de Recursos Hídricos, 21(4), 821-831.

Empresa Brasileira de Pesquisa Agropecuária - EMBRAPA. (1999). Sistema brasileiro de classificação de solos. Rio de Janeiro: Centro Nacional de Pesquisa de Solos.

Fahimi, F., Yaseen, Z. M., \& El-Shafie, A. (2017). Application of soft computing-based hybrid models in hydrological variables modeling: a comprehensive review. Theoretical and Applied Climatology, 128(3-4), 875-903.

Figueiredo, N. M., \& Blanco, C. J. C. (2014). Simulação de vazões e níveis de água médios mensais para o Rio Tapajós usando modelos ARIMA. Revista Brasileira de Recursos Hídricos, 19(3), 111-126.

Figueiredo, N. M., \& Blanco, C. J. C. (2017). Modelos RNA como ferramentas de previsão de afluências e de níveis de água em AHE. Revista Interdisciplinar de Pesquisa em Engenharia, 2(9), 110-123.

Flores, G., \& Ferreira, V. H. (2018). A rain-streamflow model for prediction of limnimetric behavior of reservoirs using artificial neural networks. In Simpósio Brasileiro de Sistemas Elétricos (SBSE) (pp. 1-6). New York: IEEE.

Garson, G. D. (1991). Interpreting neural-network connection weights. Artificial Intelligence Expert, 6, 47-51.

Guzman, S. M., Paz, J. O., \& Tagert, M. L. M. (2017). The use of NARX neural networks to forecast daily groundwater levels. Water Resources Management, 31(5), 1591-1603.

Haykin, S. (2008). Neural networks and learning machines. New Jersey: Prentice Hall.

Lima, P. M., \& Guedes, E. B. (2015). Rainfall prediction for Manaus, Amazonas with artificial neural networks. In 2015 Latin America Congress on Computational Intelligence (LA-CCI) (pp. 1-6). New York: IEEE.

Maier, H. R., \& Dandy, G. C. (2000). Neural networks for the prediction and forecasting of water resources variables: a review of modelling issues and applications. Environmental Modelling \& Software, 15(1), 101124.

McCulloch, W. S., \& Pitts, W. (1943). A logical calculus of the ideas immanent in nervous activity. The Bulletin of Mathematical Biophysics, 5(4), 115-133.

Oyebode, O., \& Stretch, D. (2019). Neural network modeling of hydrological systems: a review of implementation techniques. Natural Resource Modeling, 32(1), e12189.

Pasini, F. (1914). Relazione sul progettodella bonifica renana. Bologna, Italy: Bologna University.

Ribeiro Neto, A., Silva, R. C. V., Collischonn, W., \& Tucci, C. E. M. (2008). Simulação na bacia Amazônica com dados limitados: rio Madeira. Revista Brasileira de Recursos Hídricos, 13(3), 47-58. 
Rocha, V. M., Correia, F. W. S., Silva, P. R. T., Gomes, W. B., Vergasta, L. A., Moura, R. G., Trindade, M. S. P., Pedrosa, A. L., \& Silva, J. J. S. (2017). Reciclagem de precipitação na bacia amazônica: o papel do transporte de umidade e da evapotranspiração da superfície. Revista Brasileira de Meteorologia, 32(3), 387-398.

Sahoo, S., \& Jha, M. K. (2013). Groundwater-level prediction using multiple linear regression and artificial neural network techniques: a comparative assessment. Hydrogeology Journal, 21(8), 1865-1887.

Salame, C. W., Queiroz, J. C. B., Souza, E. B., Farias, V. J. C., Rocha, E. J. P., \& Moura, H. P. (2019). Um estudo comparativo dos modelos Box-Jenkins e redes neurais artificiais na previsão de vazões e precipitações pluviométricas da bacia Araguaia, Tocantins, Brasil. Revista Brasileira de Ciências Ambientais, (52), 28-43.

Santos Neto, L. A., Maniesi, V., Querino, C. A. S., Silva, M. J. G., \& Brown, V. R. (2020). Modelagem hidroclimatológica utilizando redes neurais multi-layer perceptron em bacia hidrográfica no sudoeste da Amazônia. Revista Brasileira de Climatologia, 26, 696-711.

Silva, A., Castro, A., \& Vieira, A. (2018). Modelo de previsão hidrológica utilizando redes neurais artificiais: um estudo de caso na bacia do Rio Xingu - Altamira-PA. Revista Brasileira de Computação Aplicada, 10(3), 5562.

Silva, I. N., Spatti, D. H., \& Flauzino, R. A. (2010). Redes neurais artificiais para engenharia e ciências aplicadas curso prático. São Paulo: Artliber.

Silva, R. S., Blanco, C. J. C., Cavalcante, I. C. S., Teixeira, L. C. G. M., Fernandes, L. L., \& Pessoa, F. C. L. (2020). Relationship between water quality parameters and land use of a small Amazonian catchment. Sustainable Water Resources Management, 6(4), 1-9.

Sudheer, K. P., Gosain, A. K., \& Ramasastri, K. S. (2002). A data-driven algorithm for constructing artificial neural network rainfall-runoff models. Hydrological Processes, 16(6), 1325-1330.

Trindade, L. L., \& Scheibe, L. F. (2019). Water management: constraints to and contributions of Brazilian watershed management committees. Ambiente \& Sociedade, 22, e02672.

Tripura, J., \& Roy, P. (2017). Flow forecasting in multiple sections of a river system. KSCE Journal of Civil Engineering, 21(2), 512-522.

Wunsch, A., Liesch, T., \& Broda, S. (2018). Forecasting groundwater levels using nonlinear autoregressive networks with exogenous input (NARX). Journal of Hydrology, 567, 743-758.

\section{Contribuições dos autores:}

Leonardo Melo de Mendonça: concepção do trabalho, escrita geral, levantamento bibliográfico e de dados; análise dos resultados e revisão geral do artigo.

Igor de Souza Gomide: revisão geral do artigo, análise dos resultados, escrita geral.

Jaime Viana de Sousa: revisão geral do artigo, análise dos resultados, escrita geral.

Claudio José Cavalcante Blanco: revisão geral do artigo, análise dos resultados, escrita geral. 